\title{
Francisco de Assis e o Sultão: uma relação de encontro e diálogo
}

\author{
Daison Fermino de Sá ${ }^{1}$
}

\begin{abstract}
Resumo
O presente trabalho tem como pressuposto o documento conciliar, Nostra Aetate, e pretende perceber em Francisco de Assis propostas de diálogo e aproximação inter-religiosa a partir do seu encontro com o sultão muçulmano. O texto pretende relacionar o significado desse encontro histórico com os fundamentos de diálogo inter-religioso propostos em Nostra Aetate.
\end{abstract}

Palavras-chaves: Nostra Aetate; Francisco de Assis; Diálogo.

\begin{abstract}
The present work is based on the concise document, Nostra Aetate, and is able to understand in Francis of Assisi proposals for interreligious dialogue and rapprochement from his meeting with the Muslim sultan. The text intends to relate or the meaning of this historical encounter with the foundations of interreligious dialogue proposed in Nostra Aetate.
\end{abstract}

Key Words: Nostra Aetate; Francis of Assis; Dialogue.

\section{Introdução}

O Concílio Ecumênico Vaticano II foi proclamado pelo Papa São João XXIII no dia 25 de janeiro de 1959. Um momento de virada copernicana na Igreja. Segundo Libânio, pode-se ver o Concílio a partir de duas perspectivas ${ }^{2}$, a saber, como continuidade dos dois concílios anteriores ou como uma novidade inaugurada. Com a morte do Papa João XXIII, o Concílio foi conduzido até o seu final em 1965, pelo Papa Paulo VI. O Concílio Vaticano II ofereceu à Igreja um retorno às fontes da Sagrada Escritura e da Patrística que influenciou uma revisão de sua eclesiologia. Por exemplo, na Constituição Dogmática sobre a Igreja, Lumen Gentium, expressou a comunhão de todos os batizados, ministros ordenados, consagrados e leigos com a noção de Povo de Deus rumo à Pátria

\footnotetext{
${ }^{1}$ Mestrando pela Pontifícia Universidade Católica do Rio Grande do Sul.

2 LIBÂNIO, João Batista. Concílio Vaticano II. Em busca de uma primeira compreensão, p. 9.
} 
definitiva. Igualmente propõe um importante diálogo com o mundo, para que possa levar a Boa Nova de Cristo às diversas realidades seculares. Essa renovação conciliar se expressa nas constituições, decretos e declaração, inclusive sua forma de dialogar com outras religiões, como demonstra a declaração Nostra Aetate.

Considerando o documento conciliar, Nostra Aetate, passamos a analisar o encontro de São Francisco de Assis com o sultão muçulmano, para perceber possíveis inspirações de diálogo e aproximação inter-religiosa não só com o mundo islâmico atual, mas de modo geral com outras religiões. São Francisco de Assis, no século XIII se lançou a um desafio extremamente arriscado. O período era de muito confronto, guerras e cruzadas. Mesmo diante dessa realidade nada favorável à paz, Francisco vai ao encontro o sultão do Egito, Malik Al-Kamil, abrindo um dos mais relevantes precedentes para o diálogo inter-religioso entre islâmicos e cristãos. Vale recordar que o encontro de Francisco com o mulçumano revela ser possível no meio de posturas arriscadas e ter atitudes de diálogo e compreensão.

\section{Nostra Aetate: Diálogo Inter-Religioso}

A janela aberta pelo Concílio Ecumênico Vaticano II e os novos ares que entraram na Igreja, propiciaram repensar e inaugurar um novo período de Pentecostes na vida eclesial. Um dos objetivos do Concílio era fortalecer a vocação da missão da Igreja.

O próprio discurso de João XXIII, que abriu o Concílio, mostrava a importância da atenção aos sinais dos tempos, a importância do aggiornamento da Igreja, a importância de saber distinguir a substância dos dogmas e sua formulação histórica. Ao realizar tais afirmações, estava tocando em algo considerado intocável durante séculos: a "imutabilidade da fé e a imutabilidade da Igreja" 3.

Um dos aspectos muito importante trabalhado e refletido no Concílio foi a relação da Igreja com o mundo, e as mais variadas expressões que vem acontecendo no seio da sociedade contemporânea. Dentre tantos documentos

\footnotetext{
3 DOTTO, Olavo José. O povo de Deus como sujeito da comunhão e participação na vida da Igreja. Abordagem teológico-pastoral dos escritos de Dom Aloísio Lorscheider em vista de uma prática cristã. (Tese de Dissertação). Belo Horizonte: FAJE, 2011, p. 43.
} 
conciliares, a constituição Gaudium et Spes, apresenta uma Igreja que dialoga com o mundo. E “o Concílio visa promover o "mútuo conhecimento e apreço” por meio de estudo da Bíblia, da reflexão teológica “e ainda por diálogos fraternos” 4.

Pode-se chamar a atenção de que Nostra Aetate constitui-se de um texto que "em si não é um Documento de diálogo, mas sim um texto que declara a disposição da Igreja para tal. O Documento nem operacionaliza o conceito do diálogo nem concretiza aspectos como os pré-requisitos e possíveis assuntos de um intercâmbio entre as religiões" 5 .

Afirma o documento da Nostra Aetate,

Com efeito, os homens constituem todos uma só comunidade; todos têm a mesma origem, pois foi Deus quem fez habitar em toda a terra o inteiro género humano; têm também todos um só fim último, Deus, que a todos estende a sua providência, seus testemunhos de bondade e seus desígnios de salvação até que os eleitos se reúnam na cidade santa, iluminada pela glória de Deus e onde todos os povos caminharão na sua luz. Os homens esperam das diversas religiões resposta para os enigmas da condição humana, os quais, hoje como ontem, profundamente preocupam seus corações: que é o homem? qual o sentido e a finalidade da vida? que é o pecado? donde provém o sofrimento, e para que serve? qual o caminho para alcançar a felicidade verdadeira? que é a morte, o juízo e a retribuição depois da morte? finalmente, que mistério último e inefável envolve a nossa existência, do qual vimos e para onde vamos? ${ }^{6}$

Percebe-se a noção de ver todos os seres humanos como criaturas de Deus, por isso, a forma relacional tem que partir deste reconhecimento. Há uma esperança escatológica presente nessa relação de reconhecimento, onde todos estarão juntos no caminho da salvação divina. Todos formam uma única comunidade.

Essa declaração do concílio gerou na Igreja algumas atitudes muito interessantes, alguns passos foram dados para que, de fato, pudesse ser mostrado o compromisso abraçado. Geffré, brevemente apresenta um relato de ações que aconteceram sob a influência da declaração.

\footnotetext{
${ }_{4}$ USARSKI, Frank. Nostra Aetate. In: PASSOS, João D.; SANCHES, Wagner L. Dicionário do Concílio Vaticano II, 667.

5 USARSKI, Frank. Nostra Aetate, 670.

${ }^{6}$ Nostra Aetate, n. 1.
} 
Essa nova atitude concretizou-se nos gestos de alto alcance simbólico feito, sobretudo pelo papa João Paulo II: sua visita ao grande Rabino da sinagoga de Roma, seu discurso aos jovens muçulmanos no estádio de Casablanca em 1985 e, sobretudo, o famoso encontro em Assis em outubro de 1986, que reunia vários dos grandes líderes das religiões do mundo para uma oração a favor da paz. E, mais próximo de nós, não podemos subestimar a peregrinação do bispo de Roma a Jerusalém com a visita a Yad Vashem - lugar da memória do Holocausto - e ao Muro da lamentação, sem esquecer a recentíssima visita à mesquita dos Omayadas de Damasco. Se se pensa nos conflitos seculares da igreja católica tanto com o judaísmo como com o Islã e na ignorância prática em que ela deixava as outras tradições religiosas, não é exagerado falar de uma evolução verdadeiramente revolucionária.7

É necessário perceber a riqueza que há na Nostra Aetate, pois segundo Geffré "é preciso situar a importância verdadeiramente histórica da nova atitude da Igreja Católica, depois do Concílio Vaticano II, diante das religiões nãocristãs"8. O próprio documento afirma que "a Igreja Católica nada rejeita do que há de verdadeiro e santo nestas religiões" 9.

A declaração conciliar apresenta algumas considerações acerca do relacionamento humano a partir das religiões, que por muitas vezes entram em conflito e discórdia, assim diz o documento,

a Igreja, que reprova quaisquer perseguições contra quaisquer homens, lembrada do seu comum patrimônio com os judeus, e levada não por razões políticas mas pela religiosa. caridade evangélica. deplora todos os ódios, perseguições e manifestações de antissemitismo, seja qual for o tempo em que isso sucedeu e seja quem for a pessoa que isso promoveu contra os judeus ${ }^{10}$.

Lembra-se, por mais que visa buscar uma aproximação respeitosa e até mesmo um diálogo com outras religiões a Igreja, neste documento deixa claro que,

De resto, como a Igreja sempre ensinou e ensina, Cristo sofreu, voluntariamente e com imenso amor, a Sua paixão e morte, pelos pecados de todos os homens, para que todos alcancem a salvação. O dever da Igreja, ao pregar, é portanto, anunciar a cruz de Cristo

\footnotetext{
7 GEFFRÉ, Claude. Para uma nova teologia das religiões. In: Rosino, GIBELLINI (Ed.). Perspectivas teológicas para o século XXI, p. 321

${ }^{8}$ GEFFRÉ, Claude. Para uma nova teologia das religiões, p. 321.

9 Nostra Aetate, n. 2.

${ }^{10}$ Nostra Aetate, n. 4
} 
como sinal do amor universal de Deus e como fonte de toda a graça. ${ }^{11}$

E, mais, “a Igreja reprova, por isso, como contrária ao espírito de Cristo, toda e qualquer discriminação ou violência praticada por motivos de raça ou cor, condição ou religião."12

O documento conciliar também faz referência a algumas religiões, de forma especial as grandes religiões do mundo: hinduísmo, o budismo, o islã e o judaísmo. Especificamente sobre a religião muçulmana, sustenta:

A Igreja olha também com estima para os muçulmanos. Adoram eles o Deus Único, vivo e subsistente, misericordioso e omnipotente, criador do céu e da terra, que falou aos homens e a cujos decretos, mesmo ocultos, procuram submeter-se de todo o coração, como a Deus se submeteu Abraão, que a fé islâmica de bom grado evoca. Embora sem o reconhecerem como Deus, veneram Jesus como profeta, e honram Maria, sua mãe virginal, à qual por vezes invocam devotamente. Esperam pelo dia do juízo, no qual Deus remunerará todos os homens, uma vez ressuscitados. Têm, por isso, em apreço a vida moral e prestam culto a Deus, sobretudo com a oração, a esmola e o jejum ${ }^{13}$

E recomenda ainda que

se é verdade que, no decurso dos séculos, surgiram entre cristãos e muçulmanos não poucas discórdias e ódios, este sagrado Concílio exorta todos a que, esquecendo o passado, sinceramente se exercitem na compreensão mútua e juntos defendam e promovam a justiça social, os bens morais e a paz e liberdade para todos os homens. ${ }^{14}$

Ainda sobre os muçulmanos, a Declaração afirma que o

Deus testemunhado por eles compartilhar diversos elementos com o do Cristianismo, particularmente a adoração Dele como "vivo e subsistente, misericordioso e onipotente" e como "Criador do céu e da terra" bem como a esperança do Dia do Juízo e suas implicações soteriológicas. ${ }^{15}$

Diante de todas as questões levantadas no documento, a Igreja não se reduz apenas ao reconhecimento de alguns elementos e/ou práticas não cristãs, "mas postula que os aspectos positivos têm a função de abrir os seguidores dessas

\footnotetext{
${ }^{11}$ Nostra Aetate, $n .4$

${ }^{12}$ Nostra Aetate, n. 5

${ }^{13}$ Nostra Aetate, n. 3

${ }^{14}$ Nostra Aetate, n. 3

15 USARSKI, Frank. Nostra Aetate, 666.
} 
religiões para o Evangelho, isto é, a mais completa e única realmente satisfatória mensagem divina". ${ }^{16}$

Lembra Gefré que a

declaração Nostra Aetate propunha certa ética do diálogo com as outras religiões, mas não apresentava um fundamento teológico capaz de justificar claramente o diálogo encorajado pela igreja. $\mathrm{O}$ documento conciliar pronuncia um juízo positivo sobre a religiões não-cristãs, mas não se exprime em termos explícitos sobre a relação positiva que as diversas religiões possam ter com o Absoluto. Ele faz referência à doutrina patrística das "sementes do Verbo", sem elaborar uma verdadeira teologia das religiões ${ }^{17}$.

\section{Encontro de São Francisco com o Sultão muçulmano}

Por volta de 1181/ 1182, nasceu em Assis o filho de Pedro de Bernardone, comerciante e Dona Joana, provavelmente com apelido de Picca. No Batismo recebeu o nome de João Batista. O pai, ao regressar de uma viagem passou a chamá-lo de Francesco, pequeno francês. Na guerra entre Assis e Perugia, Francisco participou, com desejo de se tornar o "cavaleiro" vencendo a disputa. Os nobres de Assis, aliados à Perugia, causaram uma grande derrota aos "burgueses" de Assis. Francisco foi feito prisioneiro e passou um tempo nos cárceres de Perugia, onde caiu enfermo e foi resgatado pelo pai. Francisco passou por longa enfermidade. Após a melhora, procurou ingressar no exército papal, para assim, conseguir alcançar o seu sonho. Seus planos mudaram completamente quando ele decidiu tomar um novo rumo na vida, aproximando-se dos mais pobres de Assis.

Em 1206, ano considerado central de sua conversão, ele viveu importantes experiências que determinaram essa mudança de perspectiva de deus sonhos e seu estilo de vida: despojamento diante do bispo Guido II, o abandono da casa paterna, o isolamento em uma gruta, a oração diante do crucifixo da Igreja de São Damião, o encontro com o leproso, e a prestação de serviço no cuidado dos leprosos. Passou a vestir hábito de eremita e iniciou a restauração da igrejinha de São Damião. A partir de então, tomou um rumo novo à sua vida. Suas ações eram em torno do Evangelho de Cristo e dos leprosos de sua época.

\footnotetext{
16 USARSKI, Frank. Nostra Aetate, 670.

17 GEFFRÉ, Claude. Para uma nova teologia das religiões, p. 322.
} 
Após algum tempo de sua conversão, Francisco se dirige a região da Síria, período de fortes conflitos entre cristãos e pagãos.

Na biografia de São Francisco, escrita por Celano ${ }^{18}$, se encontra a descrição do fato:

No décimo terceiro ano de sua conversão, [...] E, embora tivesse sido maltratado por muitos com ânimo bastante hostil e com espírito adverso, no entanto, foi recebido pelo sultão com muita honra. Honrava-o como podia e, tendo-lhe oferecido muitos presentes, tentava dobrar o espírito dele às riquezas do mundo; mas depois que o viu desprezar valorosamente tudo como esterco, encheu-se de máxima admiração e via-o como homem diferente de todos; ficou muito tocado pelas palavras dele e ouvia-o de muito bom grado (cf. Mc 6,20). - Em todas estas coisas o Senhor não realizou o desejo (cf. Sl 126,5) dele, reservando-lhe a prerrogativa de uma graça especial ${ }^{19}$

Francis de Beer apresenta o relato sob duas perspectivas, uma contada pelos estranhos à Ordem e a outra pelos próprios irmãos. Na primeira, Beer diz que o primeiro testemunho é o de Jacque de Vitry, bispo de São João de Acre, viu Francisco indo em direção a Damieta rumo ao palácio do Sultão em 1219. ${ }^{20} \mathrm{O}$ autor comenta que "a chegada à Damieta do célebre Irmão Francisco, bem-amado de Deus e dos homens, abre uma pausa de novidade e surpresa”. ${ }^{21}$ Com relação à segunda perspectiva, Beer relata que Tomás Celano narra que o "encontro com Islão será relacionado como desejo do martírio que abrasava Francisco desde a sua conversão" 22 . Beer conclui a análise:

na medida em que os cronistas de fora da Ordem situam o encontro de Francisco com o Islão no quadro da problemática da Cruzada, em igual medida os Irmãos Menores teriam a tendência a isolá-lo, para compreendê-lo em referência com um incoercível desejo do martírio[...] deixam bem fundamentado o valor histórico do acontecimento. Sem dúvida, essa viagem podia ter dado ensejo

\footnotetext{
${ }^{18}$ Sobre Celano, na verdade, são bem poucos os dados que se possuí da vida e personalidade do mesmo, sendo ele o primeiro biógrafo de São Francisco. A data de nascimento dele se coloca entre 1185 e 1190 . O certo é que por volta de 1215, ao se agregar a fraternidade franciscana, já era adulto, intelectualmente maduro e certamente sacerdote. (Fonte: FONTES FRANCISCANAS E CLARIANAS. 3ed. Petrópolis: Vozes, 2014, p. 20).

19 CELANO, Tomás. Primeira Vida de São Francisco - Frei Tomás de Celano. In: Fontes Franciscanas e Clarianas. 3ed. Petrópolis: Vozes, 2014, pp. 236-237. (1 Celano 57, 5.8-12)

${ }^{20}$ Com relação a data recorda-se que entre os biógrafos e historiadores não há uma unanimidade de quando aconteceu o encontro. (Fonte: BASETTI-SANI, G. Sarracenos. In. Movimento franciscano Assisi. Dicionário Franciscano. Petrópolis: Cefepal/Vozes, 1999, p.696).

${ }^{21}$ BEER, F. São Francisco e o Islão. In: Concilium. V. 17, fasc 169. Petrópolis: Vozes, 1982.p. 17

${ }_{22}^{2}$ BEER, F. São Francisco e o Islão, 1981, p. 19
} 
8 | Opinião Filosófica, V. 10, n. 2, 2019 - Brasil Filosófico e seus pensadores

a lendas. Mas deve-se sublinhar energicamente que, neste caso preciso, elas sempre são ouvidas às portas da história. ${ }^{23}$

Em pleno cerco de Damieta, local do encontro, "o Sultão não consegue ver em Francisco um Cruzado, e Francisco não reconhece tampouco no Sultão o perseguidor da fé que esperava". 24 Para Beer, três observações acerca da aventura vivida por Francisco podem ser identificadas: a) Francisco realmente acreditou inicialmente que o seu eventual martírio iria falar ao Islão; b) Francisco teria sido recebido com maus tratos em Damieta, onde foi perseguido como qualquer outro cruzado; e c) Francisco realizou uma pregação cristã, um querigma, e o Sultão o escutou de bom grado, mas não assumiu nenhuma posição 25 .

Segundo Basetti-Sani, o muçulmano que Francisco encontrou no Egito não era uma pessoa temida, no sentido em que era um carrasco,

Melek-el-Kamel era realmente um homem justo e piedoso e não um "ferocíssimo sultão" como o apresentam os documentos cristãos, sempre com a inconsciente tendência de apresentar os muçulmanos sob um ângulo negativo. Há em todos, mesmos escritores franciscanos e outros da Idade Média, uma mentalidade herdada, marcada pela característica antimuçulmana ${ }^{26}$.

Lembra ainda Basetti que a "cristandade medieval sentia-se cercada pelo mundo muçulmano e via no Islão a força diabólica” 27 . Para explicar a recusa dos “doutores muçulmanos" em discutir a questão de fé, convém colocar o relato dos biógrafos no contexto da história e da psicologia do Islã. Até hoje o gesto de Francisco não foi compreendido em todo o seu alcance. Fala-se de "solidificação de uma intuição, por mais bela e atraente que seja, mas subjetiva e caso isolado na realidade histórica, na visão que Massignon tinha da história, a função de substituição que Francisco providencialmente tinha da história no sentido de completar o que tinha faltado à missão de Maomé”. ${ }^{28}$.

Diz Basetti-Sani,

\footnotetext{
23 BEER, F. São Francisco e o Islão, 1981, p. 21

24 BEER, F. São Francisco e o Islão, 1981, p. 22

25 BEER, F. São Francisco e o Islão, 1981, pp. 24-25

${ }^{26}$ BASETTI-SANI, G. Sarracenos. In. Dicionário Franciscano. Petrópolis: Cefepal/Vozes, 1999, p. 697

${ }^{27}$ BASETTI-SANI, G. Francisco de Assis: a crise da igreja pelos fins do século XII, princípios do século XIII. In. Concilium, v. 4, fasc 37. Petrópolis: Vozes, 1968, p.14

${ }^{28}$ BASETTI-SANI, G. Sarracenos, 1999, p. 697
} 
não excluo que o Sultão tivesse dito: "creio que vossa fé seja boa e verdadeira. E a partir de então teve a fé cristã impressa no coração (Misc. Bon. 5). Todo autentico muçulmano sabe que o judaísmo e o cristianismo são religiões provenientes de Deus e por isso verdadeiras, embora inferiores ao islamismo. É neste sentido que se deve entender a frase do Sultão. ${ }^{29}$

A experiência vivida por Francisco naquele encontro foi tão marcante que ele faz questão de registrar na regra de vida para os frades. Trata-se de uma regra que foi escrita para ter aprovação da Igreja na evangelização e assim, o grupo seguidor de Francisco, ser considerado uma Ordem Religiosa. Na realidade foram escritas três regras. Uma não se sabe o que aconteceu, outra chamada regra não bulada, isto é, não recebeu aprovação papal e última é regra bulada, aprovada pelo papa. Mencionam-se essas regras para relatar que nas duas regras, não bulada e a bulada, Francisco faz questão de citar o encontro com o Sultão. Um dos elementos descritos da forma de vida é sobre "os que vão para o meio dos sarracenos e outros infiéis", e trata justamente desse relacionamento.

Baseado nestas recomendações que Francisco faz aos seus confrades no capítulo 16 da Regra Não-Bulada, é possível desenvolver um modelo de inspiração para um relacionamento de cristãos com pessoas de outra religião. Esta forma sugerida por Francisco é o que se poderia chamar de "atitude franciscana no diálogo inter-religioso”. Esta não constitui um modelo único, nem uma receita para se proceder no diálogo inter-religioso. Trata-se sim antes de tudo de uma atitude, de uma forma de agir e portarse que pré-dispõe e dispõe para o diálogo ${ }^{30}$.

Esse contato de Francisco com sultão, um tanto desafiador, ao mesmo tempo apresenta uma forma de relações. Tanto a postura de Francisco quanto a do sultão, revelam tratamento de respeito e diálogo. Cada vez mais, se clama por uma postura de cordialidade e compreensão nas opções religiosas nos seus diferentes credos, confissões de fé.

\section{O diálogo Inter-Religioso}

Após termos nos dedicado a uma breve reflexão sobre o documento

\footnotetext{
29 BASETTI-SANI, G. Sarracenos, p. 698

$3^{30}$ BERKENBROCK, V. A atitude franciscana e o diálogo inter-religioso. In: MOREIRA, A.S. (Org) Herança Franciscana, p. 20.
} 
conciliar, Nostra Aetate, e constatado o significado do encontro de Francisco de Assis com o sultão muçulmano, nos lançamos a perceber como esse fato histórico pode inspirar no diálogo entre as religiões.

Claude Geffré diz que,

no limiar do século XXI, o desafio maior da teologia cristã não vem tanto da multiplicidade das religiosidades de tipo sincretístico ou esotérico, que passam sob a cômoda etiqueta de New Age, quanto a pluralidade das grandes religiões não-cristãs que nós vimos a conhecer sempre melhor e que dão, muitas vezes, prova de uma nova vitalidade. ${ }^{31}$

É preciso estar atento e perceber o poder de sedução e o dinamismo das religiões, pois elas já não estão fixadas apenas nos seus lugares de origem, mas avançam para tantos lugares, por onde não se pensava que pudessem um dia chegar.

o pluralismo religioso tende a ser tornar o horizonte da teologia do século XXI e nos convida a revisitar os grandes capítulos de toda a dogmática cristã. Trata-se da resposta a uma situação histórica e incontestável e também da consequência de uma intuição-chave do concílio Vaticano II que, pela primeira vez na história do magistério romano, deu um juízo positivo sobre as religiões nãocristãs ${ }^{32}$.

Muitas vezes pode parecer que a busca do diálogo, seja inviável, pois pode haver maiores confrontos e discordâncias, gerando assim um afastamento, como relata Geffré, que "diante das ambiguidades da mundialização, o diálogo interreligioso representa uma chance na medida em que ele pode contrabalançar os efeitos perversos de uma cultura sempre mais uniforme sob o signo do consumismo, da obsessão do lucro e de um hedonismo fácil" 33 . Em contrapartida, se faz necessário unir as expressões religiosas para que as ambiguidades da mundialização não prevaleçam nos relacionamentos humanos.

O próprio documento conciliar também chama a atenção para as relações no âmbito inter-religioso. Exorta, por isso, os seus filhos a que, com prudência e caridade, pelo diálogo e colaboração com os sequazes doutras religiões, dando

\footnotetext{
${ }^{31}$ GEFFRÉ, Claude. Para uma nova teologia das religiões, 2005, p. 319

${ }^{32}$ GEFFRÉ, Claude. Para uma nova teologia das religiões, 2005, p. 319

33 GEFFRÉ, Claude. Para uma nova teologia das religiões, 2005, p. 321
} 
testemunho da vida e fé cristãs, reconheçam, conservem e promovam os bens espirituais e morais e os valores sócio culturais que entre eles se encontram.34

A experiência de Francisco, seu carisma e espiritualidade apresentam modos de relacionamento. O desafio por ele vivido vale para ainda hoje: procurar aproximar-se, escutar o outro e compreender, exige atitudes de fraternidade, e minoridade. A proximidade é consequência de uma procura, procura essa que é pelo bem-estar dos outros. Nesse mundo carregado de violência, tal como aquele de Francisco, é preciso resgatar e trabalhar pela paz. Dessa forma, compreenderse-á alguns desses elementos que encontra no carisma vivenciado por Francisco de Assis, como proposta de relacionamento e diálogo inter-religioso, a saber, fraternidade e minoridade; o desejo pela paz.

\section{Fraternidade e minoridade}

A fraternidade um valor eminente de São Francisco, em sua forma de vida. Impelido pelo Espírito do Senhor, ele deixou-se mover de forma natural as relações. A fraternidade franciscana "se traduz essencialmente pelo testemunho oferecido ao mundo da paternidade universal de Deus e da fraternidade universal de homem $35 "$.

Segundo Basetti-Sani,

A sinceridade e doçura com que o Santo e Frei Iluminato de Rieti se apresentaram na sua missão de enviados de Deus causou admiração e logo suscitou veneração e estima. Aquela atitude de humildade e bondade, verdadeiramente "cristã", nada tinha de comum com o espírito orgulhoso e violento dos cruzados. Achavase a consciência religiosa de Melek el-Kamel, homem pio e justo, disposta a aceitar o testemunho de um "portador da Palavra de Deus $^{36}$.

O fato de se aproximar despojado, humildemente, faz com que o encontro seja sincero e autêntico, isto é tornar-se o menor. Eis o desafio apresentado. E mais, diria ainda Basetti-Sani se referindo aos biógrafos, Celano e São Boaventura, que escreveram o relato do encontro de Francisco e sultão:

\footnotetext{
34 Nostra Aetate, n. 2.

35 BONI, Andrea. Fraternidade. In. Dicionário Franciscano. Petrópolis: Cefepal/Vozes, 1999. p. 271 ${ }^{36}$ BASETTI-SANI, G. Francisco de Assis: a crise da igreja pelos fins do século XII, princípios do século XIII, p. 21
} 
12 | Opinião Filosófica, V. 10, n. 2, 2019 - Brasil Filosófico e seus pensadores

Dizem Celano e São Boaventura que o sultão logo se apercebeu do fervor de espírito e da santidade do Frade, que não teve qualquer palavra de desprezo, nem pela pessoa de Maomé, nem pelo Corão. Não era realmente fácil imaginar um cristão latino da Idade Média dirigir-se aos muçulmanos sem lhes mostrar qualquer desprezo pela sua religião nem insultar o profeta. São Francisco guardou o respeito pelas pessoas, dentro do verdadeiro espírito do Evangelho, por toda a parte reconhecendo ação de Deus, inclusivamente entre os muçulmanos. Declara-se disposto a aceitar o convite do sultão para que não parta, por amor de Cristo, mas deseja, porém dar testemunho da fé cristã mediante o ordálio de fogo 37 .

Aproximar-se do diferente exige quebrar preconceitos e romper paradigmas. Bingemer ajudar a compreender qual é a proposta do diálogo:

A transformação, portanto, que o diálogo requer é uma transformação da forma de ver o outro e sua religião e sua prática religiosa. É uma tentativa honesta e séria de sair da ignorância sobre sua alteridade e sua identidade. Em outras palavras, a salvação que pode advir a mim a partir da religião do outro é uma transformação de perspectiva, de juízo e avaliação ${ }^{38}$

\section{Desejo pela paz}

O fato de Francisco de Assis ser uma referência para o diálogo interreligiosos e deve à expressão do desejo dele para que todos sejam instrumentos de paz. "Deus deseja a paz desde o princípio, e criando o ser humano à sua imagem e semelhança, quer possibilitar que em cada homem e em cada mulher aconteça o desejo do Reino de Deus, que é um desejo de paz"39.

Basetti-Sani, lembra que Francisco tem esse desejo que é inspirado por Deus:

Francisco, inspirado por Deus, compreendeu que a primeira coisa que precisa fazer era anunciar a pacificação das almas dos cristãos. Em nome de Cristo morto para a pacificação de todos os homens, justificar a guerra dos cristãos tida como "justa e santa" contra os "infiéis" chamados de "inimigos da cruz de Cristo" era aos olhos de Francisco aviltar a "loucura da cruz" ao nível da sabedoria e da prudência humana. ${ }^{40}$

37 BASETTI-SANI, G. Francisco de Assis: a crise da igreja pelos fins do século XII, princípios do século XIII, p. 21.

${ }^{8}$ BINGEMER, Maria Clara Lucchetti (Org). Violência e Religião: Cristianismo, Islamismo, Judaísmo - três religiões em confronto e diálogo, p. 287.

39 BINGEMER, Maria Clara Lucchetti (Org). Violência e Religião, 2001. p. 283.

40 BASETTI-SANI, G. Sarracenos, 1999, pp. 692-693. 
Essa inspiração vivida por Francisco torna-se um espelho para as relações e o diálogo inter-religioso. Ele soube constatar que sua missão, recebida por Deus, não aceita a discórdia e violência, pois assim estaria sendo contrário sua própria fé. Dessa forma, "São Francisco ajuda a cristandade a dissociar a reforma religiosa da cruzada guerreira, que pretendia vencer o Islão pela violência. Em vez disso, ele anuncia a Paz do Evangelho, que é dom do alto, e a vitória de Cristo alcançada pela Paixão e Morte"41.

\section{Considerações finais}

Diante da pluralidade religiosa contemporânea, é importante conhecer elementos que favoreçam o diálogo inter-religioso. O encontro de Francisco de Assis e o sultão apresenta uma perspectiva oportuna para tal desafio. Elementos chaves como fraternidade, minoridade e paz, podem aproximar os seres humanos para viverem o diálogo entre as tradições religiosas.

Em Francisco de Assis o desafio de se rebaixar, no sentido de humildade, parece ser um grande desafio, diante de uma sociedade voltada para o aspecto egoísta. Numa sociedade onde o pluralismo prevalece, isto é, as diferenças sociais, culturais, religiosas são demasiadas, é necessário procurar forças de união.

\section{Referências}

BASETTI-SANI, G. Sarracenos. In. Dicionário Franciscano. Petrópolis: Cefepal/Vozes, 1999, p.691-700.

BASETTI-SANI, G. Francisco de Assis: a crise da igreja pelos fins do século XII, princípios do século XIII. In. Concilium, v. 4, fasc 37. Petrópolis: Vozes, 1968, p.10-24.

BEER, F. São Francisco e o Islão. In: Concilium. V. 17, fasc 169. Petrópolis: Vozes, 1982.

BERKENBROCK, V. A atitude franciscana e o diálogo inter-religioso. In: MOREIRA, A.S. (Org.) Herança Franciscana. Petrópolis: Vozes, 1996.

${ }^{41}$ BASETTI-SANI, G. Francisco de Assis: a crise da igreja pelos fins do século XII, princípios do século XIII, 1968, p. 17 
BINGEMER, Maria Clara Lucchetti (Org.). Violência e Religião: Cristianismo, Islamismo, Judaísmo - três religiões em confronto e diálogo. São Paulo: Loyola/ PUC-Rio 2001.

Declaração Nostra Ætate. In: Documentos do Concílio Vaticano II: constituições, decretos, declarações.

DOTTO, Olavo José. O povo de Deus como sujeito da comunhão e participação na vida da Igreja. Abordagem teológico-pastoral dos escritos de Dom Aloísio Lorscheider em vista de uma prática cristã. (Tese de Dissertação). Belo Horizonte: FAJE, 2011.

FERNANDES, Fátima Regina. Cruzadas na Idade Média. In: MAGNOLI, D. História das guerras. São Paulo: Contexto, 2006.

FONTES FRANCISCANAS E CLARIANAS. 3ed. Petrópolis: Vozes, 2014.

GEFFRÉ, Claude. Para uma nova teologia das religiões. In: Rosino GIBELLINI (Ed.). Perspectivas teológicas para o século XXI. Aparecida: Santuário, 2005, p. 319-360.

USARSKI, Frank. Nostra Aetate. In: PASSOS, João D.; SANCHES, Wagner L. (Org.). Dicionário do Concílio Vaticano II. São Paulo: Paulus, 2015 (pp. 666-671).

Recebido em: 04/11/2019.

Aprovado em: 01/12/2019. 